\title{
Inside a Cultural Agency: Team Ethnography and Knowledge Exchange
}

\section{Philip Schlesinger, Melanie Selfe \& Ealasaid Munro}

To cite this article: Philip Schlesinger, Melanie Selfe \& Ealasaid Munro (2015) Inside a Cultural Agency: Team Ethnography and Knowledge Exchange, The Journal of Arts Management, Law, and Society, 45:2, 66-83, DOI: 10.1080/10632921.2015.1039741

To link to this article: https://doi.org/10.1080/10632921.2015.1039741

\section{(c) 2015 The Author(s). Published with license by Taylor \& Francis (C) Philip Schlesinger, Melanie Selfe, and Ealasaid

Published online: 30 Jun 2015.

\section{Submit your article to this journal $\sqsubset$}

\section{山 Article views: 916}

\section{Q View related articles $\widetilde{ }$}

View Crossmark data \lceil

4 Citing articles: 8 View citing articles $₫$ 


\title{
Inside a Cultural Agency: Team Ethnography and Knowledge Exchange
}

\author{
Philip Schlesinger, Melanie Selfe, and Ealasaid Munro \\ University of Glasgow, Glasgow, United Kingdom
}

\begin{abstract}
This article undertakes an auto-critical analysis of the research team's ethnographic study of Cultural Enterprise Office (CEO), a Scottish creative business support agency. We discuss the team's composition and how this relates to other analyses of ethnographic teamwork. Our research is situated in the wider policy context of the "creative-economic" turn in the UK's research funding. This has been accompanied by increased emphasis on "knowledge exchange" and "impact" in the drive for greater accountability in higher education. The team's evolution in the course of undertaking research is illustrated by reference to four "pivotal moments," which illustrate how we "performed" knowledge exchange.
\end{abstract}

Keywords creative economy, cultural enterprise, ethnography, knowledge exchange, performance, teamwork

\section{INTRODUCTION}

In this article, we reflect on our experience of working as an ethnographic team while engaged in a study of a Scottish cultural agency, Cultural Enterprise Office (CEO). So far as we can ascertain, in its precise focus, as well as in its first-time use of ethnographic teamwork in this kind of context, our study is unique, although others have researched cognate organizations with a different focus and approach (O'Connor and Gu 2010; Prince 2014).

The locus classicus for discussions of team ethnography is Erickson and Stull's (1998) perceptive and accessible slim volume. Their argument, deeply rooted in US experiences and cases, presents ethnographic team work in counterpoint to what they call the heroic "Lone Ranger" approach of going into the field, embodied in the work of anthropology's greats, such as Bronislaw Malinowski. For Erickson and Stull, the making of a team, with all the complex negotiations and arrangements that this entails, offers a positive model most crucially because it sets up a deliberative process that involves testing the work as it is being done. Much referred to in the subsequent literature, this is one key entry point into the argument.

(C) Philip Schlesinger, Melanie Selfe, and Ealasaid Munro

This is an Open Access article distributed under the terms of the Creative Commons Attribution License (http://creativecommons.org/licenses/by/3.0), which permits unrestricted use, distribution, and reproduction in any medium, provided the original work is properly cited. The moral rights of the named author(s) have been asserted.

Address correspondence to Philip Schlesinger, Centre for Cultural Policy Research, University of Glasgow, 13 Professor Square, Glasgow, G12 8QQ, United Kingdom. E-mail: philip.schlesinger@glasgow.ac.uk 
Jennifer Platt's (1976) sociology of sociological research work has also been an important point of reference. Although she addressed a particular formative moment in the expansion of British empirical sociology, her analysis offers some enduring insights. She rightly observes that any given research project is "the point of intersection of several careers" $(1976,12)$ and that this needs to be addressed as fairly as possible. It also remains the case that most, if not all, funded projects are also inherently hierarchical in their teamwork. Platt's observations about the quite different time-budgets of those on stable academic contracts and those on precarious research contracts hold today. Investigators are usually part-time because of their extensive work portfolios and accumulated busyness, whereas contract researchers are usually fully focused on the project at hand. This difference is firmly structured into the work process.

While our work adopted Platt's "democratic" style, we acknowledge the force of her observation that ultimately this depends on the Principal Investigator's (PI) approach to leadership and a willingness to decide, so far as possible, on "equity among researchers." She is right to say that in making this call, the PI demonstrates that "no team is completely non-hierarchical" $(1976,76)$.

Platt concluded that "democratic" teams tended to compromise too much and often did not meet their deadlines. While we certainly acknowledge our own rather enjoyable loquacity in team meetings, this has neither impeded keeping our project firmly on track, nor being clear about how to drive it forward. On the contrary, our lengthy and regular roundtable research team discussions undoubtedly provided the most inventive (and often amusing) moments for evaluating the fieldwork, devising presentations, writing papers, and organizing meetings.

Building on earlier work, others, such as Clerke and Hopwood $(2014,10)$, have sought to provide more developed accounts of how work is produced in teams and how this process is negotiated. We are particularly interested in the latter point, not only in respect of the delicate complexity of the internal dynamics involved but also because, for us, the structure of the team had particular significance for our relations to the structure of the organization studied.

Due to the single organization focus of the study and the depth of access we were granted, another indispensable framework for us is the sub-field of organizational ethnography. Helen Schwartzman (1993), in an incisive short review of the literature that has set the lines for much subsequent discussion, laid particular stress on the importance of meetings as a key way of understanding the functioning of an organization. The analysis of these encounters, along with the stories told by members of an organization-in particular, how such tales may constitute varied accounts of the organizational trajectory and of the part played by key individuals in making decisions - are of critical interest for any ethnographic investigation. Certainly, in our own research, the conduct and role of meetings within CEO gave us considerable insight into internal power relations and the extent to which the operating culture of the organization embodied its aims and values. The reconstruction of organizational history was essential to our understanding of CEO's present workings. The shape and ethos of the organization also strongly shaped the way in which we interacted with it.

Our research objectives and the nature of our interactions with CEO were also undeniably structured by the strategic priorities of our research funder, as the application was written in response to the UK Arts and Humanities Research Council's (AHRC's) Creative Economy Knowledge Exchange competition. This was one of a growing number of specific funding strands designed by the AHRC (the body responsible for awarding UK government funding for academic research in the sector) as a means to increase the social, economic and cultural "impact" of arts and humanities research. It has been part of a wider political imperative to demonstrate 
these disciplines' usefulness and relevance in line with an increasingly instrumental framework. While our interest in investigating the work of a cultural agency fitted easily into the "impact" rubric, the specific criteria for this funding competition left their mark on the project in three key ways. First, the study was framed explicitly in terms of the "creative economy." Second, the nature of the work and documentable outputs needed to fit within an emerging academic trend for "knowledge exchange" (KE). Third, the one-year timescale was dictated by the timing of the larger AHRC Creative Economy funding pot. We were unable, therefore, to design our project as flexibly as we would have wished to fall in line with CEO's own organizational rhythms and strategic development. Consequently, before setting out the methodological challenges we faced and the approaches we took, it is important to sketch the economic and academic policy context of the project and then provide a brief account of our object of study.

\section{CONDUCTING KNOWLEDGE EXCHANGE IN THE CULTURAL SECTOR}

Our project was titled "Supporting Creative Business: Cultural Enterprise Office and its Clients." Part of a larger initiative intended to engender "knowledge exchange" in the "creative economy," it was aligned with an established focus of UK government policy, in place since 1998. The British state has a driving interest in fostering profitable cultural production because it is seen as integral to improving the UK's ability to compete in the global economy. This policy is premised on the creative economy countering the weaknesses of other economic sectors, using "soft power" to enhance the UK's international reputation and its attractiveness as a locus for investment and tourism and, crucially, increasing the UK's international cultural trade.

The AHRC has supported numerous initiatives that have adopted this focus and consequent lines of inquiry. Although one facet of our research design was to ensure that our findings would be regularly presented to CEO throughout the fieldwork-holding up a mirror to its practice-our fundamental interest was to understand how such a body actually worked and what it could actually achieve in light of the framework of policy nostrums that gave it a raison d'être. Our study was therefore quite distinctive among the KE projects funded by the AHRC. It did not attempt to share knowledge between the academic team and those directly involved in creative ventures; nor did it aim to be a broker between different parties involved in a creative enterprise. Rather, because CEO is a support agency that aims to communicate business knowledge and skills to creative practitioners, we were engaging in a meta-study of existing KE. But, at the same time, we were involved in KE ourselves, between academia and a third sector body in the creative field.

As it happens, knowledge exchange has become a fetish and, along with "impact," an official requirement of British academic life. In undertaking the present research, we have all been committed to the idea that our work should be accessible and enlightening to those we are studying and, indeed, that it should have a wider public interest. We have willingly adopted this position in line with our own academic norms. Increasingly, however, KE has been given an obligatory official cast and is usurping and displacing academics' autonomous commitments to nominally identical goals. A typical definition of present KE doctrine, insofar as it is understood by the UK research councils, states, that "knowledge exchange is a two-way process where social scientists and individuals or organisations share learning, ideas and experiences" (Economic and Social Research Council 2014, np). While, in itself, this is hardly objectionable, it does not come 
free of baggage. Over the past 30 years, knowledge exchange-which is now coming fully into its own - has been increasingly institutionalized in the higher education sectors of North America and Europe, becoming a key mechanism for connecting business and education; it is also seen as a driver for innovation and economic growth (Kitagawa and Lightowler 2013). This raises fundamental questions about super- and subordination in the development of research. ${ }^{1}$

Schlesinger (2013) has noted elsewhere that, in the creative sector, the knowledge exchange agenda has been used to mobilize significant numbers of researchers-whether public, private, or third-sector-to ensure that the UK (and likeminded states) remain resilient and competitive in a volatile global economy. The programmatic approach to knowledge exchange promoted by the UK research councils is directly aligned with this goal. However, the official advocates of KE are strikingly incurious about what the experience of "doing" knowledge exchange might actually reveal. Our research practice strongly suggests that KE does not take the fondly imagined linear form of the arrow of knowledge moving in each—and opposite-direction. Rather, our experience of undertaking such work in the cultural sector shows just how complex and unpredictable the process can be.

The consequent need to be very flexible means that we worked out what to do as we went along; thus, we cannot report on a team ethnographic process theorized at the outset of the project and then neatly executed according to a plan. Rather, having assembled a strong three-person team with a mix of relevant skills and knowledge, we shall recount the evolution of a process of working within the field, and in response to issues encountered there, constantly adapting and reflecting on our practices. Contemporary discussions of knowledge exchange commonly fail to address precisely how the pressure to exchange knowledge, coupled with quite diverse expectations of what that knowledge actually is or the potential benefits that it might offer, profoundly shape the practical formulation of KE in the field. In what follows, therefore, we show how the knowledge exchange component of our project profoundly affected how we conducted our ethnography.

\section{INTRODUCING CULTURAL ENTERPRISE OFFICE}

Our fieldwork took place during 2013-14 in Cultural Enterprise Office (CEO), a mainly publicly funded body focused on giving business support to "creative" microbusinesses and individual traders. ${ }^{2}$ Launched in 2001, as a result of collaboration between two public agencies, the Scottish Arts Council and Scottish Enterprise Glasgow, CEO was originally a purely Glasgow-based operation designed to provide "bespoke" support to recently graduated creative practitioners, helping them to become "business ready" by developing their entrepreneurial skills. Over time, CEO's trajectory has been greatly shaped by measures taken by Scottish governments and public agencies. It has also been profoundly formed by the focus on the creative economy that has so characterized successive UK and Scottish governments' policies since 1997 (Schlesinger 2009a, 2009b). In combination with an evolving geographic remit, CEO has expanded the range of services offered and the types of client served. It currently provides business advice tailored to the creative sector through its website, phone enquiry service, one-to-one sessions, and a range of workshops. It also delivers programs targeted at different business stages and subsector needs. ${ }^{3}$ Typical of agencies of this kind, CEO's core staff is relatively small, with some 20 personnel in all, although it also brings clients together with a range of expert advisers with specialist sector and business skills. 
CEO's activity is focused on the three largest and most central Scottish cities: Glasgow (arguably the pre-eminent center of cultural life in Scotland, where the main office is located), Edinburgh, and Dundee. However, in recent years, a number of new creative sector support initiatives have emerged in these cities and beyond. CEO-which since 2009 has operated as an independent organization, answerable to a board of directors-therefore needs to work cooperatively with newer, smaller organizations, in addition to coordinating its support activities with much larger, mainstream business support agencies, such as Scottish Enterprise and Business Gateway.

CEO is therefore located in a wider Scottish cultural policy landscape. Moreover, during the period covered by our study, it was operating in a nation on the brink of voting in a referendum on major constitutional change. The issue was whether or not Scotland should become an independent state and leave the UK (Scottish Government 2013). In the event, on September 18, 2014, the vote went against independence. As a nation with its own parliament and legislative powers devolved under the Scotland Act 1998, Scotland has complete autonomy over its cultural affairs. The bulk of CEO's core funding presently comes from the Scottish Government, the country's executive and central administration, which routes the funds through the statutory agency, Creative Scotland. This is the public body that, in 2010, superseded Scottish Screen and the Scottish Arts Council to provide support across the spectrum of the arts, screen, and creative industries in Scotland. ${ }^{4}$ Therefore, just as our academic research must frame itself in relation to the priorities of our funding bodies, CEO must also develop its work pragmatically and responsively in relation to its funders and partner bodies.

Our project was initiated just as CEO was seeking to refine and consolidate its position in a support agency landscape that was in flux. Therefore, the organization's engagement with us as an academic research team was shaped by how, at various levels, CEO's personnel imagined that knowledge exchange with academic researchers might help them to articulate the agency's worth and achieve its goals. At points, this became a source of anxiety inside CEO. In particular, the fact that our main period of fieldwork was comparatively short (a consequence of the terms of our funding) and coincided with CEO's internal reorganization meant that at both director and management levels there was sometimes concern about the picture of the organization we were capturing. The key worry was that the teething troubles accompanying immediate change might be more visible than deeper practices and values. While we were acutely conscious of the challenges of researching a moving target and representing it fairly, the KE-driven imperative to feed back our tentative findings, both early and often, undoubtedly meant that our research partner's concerns were more explicitly present during the fieldwork phase than they might have been for a project with a clearer temporal separation between researching and reporting. Doing KE gave us a productive framework for testing our developing thinking with the organization, and thus refining our analyses. However, it also created occasional tensions for our continuing research relationships, which the team needed to manage with care.

Our field research began in April 2013 with observation of CEO activities, including the work conducted in their Glasgow office and the client-facing events that were being delivered throughout Scotland. Mostly undertaken in the first six months of the project, our observation of a number of key events and activities relating to services and programs continued throughout the funded period. The second, overlapping, phase of the project began in June 2013 and involved 
conducting a series of interviews with CEO personnel, and a range of its expert advisers, clients, and key stakeholders.

The next section considers the development of our ethnographic team research practices in relation to both recent literature and the project-specific factors and contexts outlined previously.

\section{DEVELOPING TEAMWORK PRACTICES IN CONTEXT}

At the outset of the project, the team sought to define what we hoped would be the ideal KE relationship - that of being a "critical friend" to the organization being researched. As the project developed, it became clear that fulfilling this role would mean setting aside some of the traditional tenets of ethnographic research. Instead of adopting an ideal-typical detached observational stance designed to minimize disruption in the field, for us to engage in the kind of knowledge exchange most useful for our partner organization meant allowing ourselves to be pulled into the day-today routines and processes of the organization and also to be drawn upon, as and when we were needed.

In terms of the particular "intersection of careers" that occurred in our project, the team consisted of the Principal Investigator (PI) - a senior, male researcher with extensive experience of ethnographic research (particularly within media and cultural institutions and organisations), and an in-depth knowledge of the Scottish policy landscape and its key actors. The female, mid-career Co-Investigator (CI) brought skills in historical organizational inquiry. The female, early-career Post-doctoral Research Associate (PDRA), our contract researcher, like the PI, had experience of organizational ethnography and extensive professional and personal contacts in the Scottish cultural and creative sector commensurate with her career stage and personal background. While none of the team members was born in Scotland, the PI had spent the larger part of his career there, and both the CI and PDRA moved to the country as children. As a result, all three team members were deeply familiar with the distinctive Scottish political, social, and cultural context in which CEO operates.

Our project conformed to one of Platt's $(1976,66-67)$ types of teamwork: "1-3 team members, director(s) working, no other resource used." Platt applied a minimalist criterion to the investigators "working," which amounted to a "degree of participation once the project has been initiated." In our case, aside from the full-time effort of the post-doc, "working" certainly went much further, as it involved an extensive commitment by the PI and CI, each of whom exceeded their respective one- and two-day buy-outs. Moreover, and crucially for present purposes, the team we put in place enabled work to proceed in line with our own division of labor. We rapidly became aware that how the team was organized - according to our own career stages and the time each could dedicate to the project-aligned helpfully with the stratification of Cultural Enterprise Office itself. CEO consisted of a Director, a small team of managers, and a larger team of junior "floor" staff.

Recent studies of ethnographic teamwork observe that the most obvious advantage is the way in which such a research group facilitates a division of labor, enabling a greater range, volume, and complexity of work to be undertaken (Mauthner and Doucet 2008, 974; Woods et al. 2000, 90). This was certainly essential for our project, in order to make the most of the exceptional access we had been granted within the limited timespan of the funding. 
It has been argued that as the size and structure of teams and projects varies greatly, so does the mix of individual tasks and collaborative effort that constitutes teamwork. At one end of the scale, are "federated" teams, coming together at the writing stage to think across the shared themes of discrete research sub-projects (Woods et al. 2000, 87). At the other-and much closer to our own experience-are smaller-scale endeavors, where overlapping involvement in data collection and a collaborative approach to analysis lead to a deeper shared knowledge of the field and a more fluid and less temporally segmented process of knowledge production (Döös and Wilhemson 2014). Whereas in some projects there is just one researcher's perspective on each element of the fieldwork (Woods et al. 2000, 85), a number of studies stress the benefits of being able to bring multiple perspectives on the same subject to the table in order to explore the differences and tensions between them (Creese et al. 2008; Gerstl-Pepin and Gunzenhauser 2002). We support this position. Observations do not need to be concurrent; nor do the overlaps need to be extensive, as having a few key triangulation points in the field data can be highly productive. Döös and Wilhemson $(2014,1097)$ note that, early on in the fieldwork process, each of their study's four research team members was involved in interviewing each of the four R\&D work teams being studied. This provided the basis for a shared understanding of the field, which was then deepened during the fieldwork period by frequent research team discussions of the latest interviews and observations. It was in these intensive but informal meetings that the emerging interpretations of the evidence could be collectively aired and tested against their theoretically driven starting point and used to develop tentative working hypotheses which informed the later, more structured and transcript-focused stages of analysis.

However, this integrated and collaborative approach to fieldwork, and the iterative production of research understanding it enables, is commonly not supported by the normative division of labor in Anglo-American qualitative research practice. More usually, there is a hierarchical split between data collection and data analysis; the Principal Investigator often does not enter the field but instead takes the lead in what then necessarily becomes a paper-driven interpretation of the findings. Drawing on Platt (1976), Mauthner and Doucet (2008, 976) argue that this "research manager" approach to ethnographic teamwork creates an internal "division of knowledge" as a consequence of its division of labor. Through the specific practices of sharing knowledge within the team, coupled with a culture of valuing objectivity and critical distance in analysis, this project-managerial approach implicitly privileges a flattened, textual account of the field as represented in transcripts and field notes, whilst devaluing the more embodied, tacit, and deeply contextual understanding that comes from being in the field. In short, it takes its distance. As they argue:

Fieldwork tends to be viewed as a technical activity that can be done by anyone, rather than an intellectual process in which meaning and knowledge are being shaped and created by subjective researchers. But to recognise fieldwork as a knowledge-producing activity means to regard contract researchers as intellectual partners equally engaged in the production and construction of knowledge, and as creative scholars drawing on their experiences of the world in "crafting" knowledge. (Mauthner and Doucet 2008, 979).

Recent work by Gupta (2014) and Middleton and Cons (2014) stresses the particular importance of contract researchers to the production of ethnographic knowledge, given the extent of their immersion in the field. Echoing Mauthner and Doucet's (2008) earlier line, Gupta (2014) suggests that, within Anglo-American ethnographic practice, the work of contract researchers 
is often not given due weight. In our project, not only was the contract researcher's knowledge valued as unique, but the PI also took an active role in the fieldwork, conducting key interviews and making observations. Moreover, it quickly became apparent that no one member of our research team was interchangeable for any other. Because of the structure of the team and the way this mapped onto the structure of the researched organization (and was perceived by its members as doing so), each of the researchers was able to access and thus construct different types of knowledge. Furthermore, while Mauthner and Doucet's primary concern has been to revalue and reposition the work of contract researchers, in the context of a KE project such as ours, there was a commitment to share and reflect on the findings with our research subjects, and to deliver insights to the partner organization both during and after the project. Not to see equal intellectual exchange as the norm within a research team working on these principles contradicts the commitment to mobilizing all resources, equitably, in the process of producing knowledge. Consequently, both we in the research team and those within CEO, the researched organization, were regularly and sometimes self-consciously involved in the process of "crafting" knowledge and performing knowledge exchange.

Crucially, as it was not expressly designed that way, we first began to understand our strengths as an ethnographic team through the ways in which CEO staff related to us, both collectively and as individuals. So, while we did not set out to perform our team structure and roles as a deliberate research strategy, once we became aware of their visibility and legibility, knowledgeable management became a crucial aspect of our ability to function in the field. To deploy Erving Goffman's (1959) famous distinction, there was an unquestionable difference between our front stage performance and how we conducted ourselves back stage. If the outward projection of the team was perceived as involving a clear hierarchy, this contrasted with the much more fluid nature of our private team interactions and routine working processes. In order to explore this duality, the remainder of this article will describe the nature of the teamwork through examples of how it operated in the field and consider the way our research meetings, written communications, and interpretative practices contributed to the production of knowledge. Throughout, we pay particular attention to exemplary moments of research and organizational "performance" and their relevance for both formal and informal moments of knowledge exchange.

\section{The Ethnographic Team in the Field}

Our ethnography of CEO took the form of extensive semi-structured interviewing $(n=26)$ of staff from across the organization (including the board, the Director, and core advisory staff). We also conducted interviews with specialist advisers $(n=12)$, key clients $(n=17)$, and stakeholders $(\mathrm{n}=11)$. We conducted extensive non-participant observation in meetings and advice sessions, as well as participant observation in other meetings, at events, and during CEO's day-to-day activities.

Due to the intensive nature of the field research, at different points in the project, the CI and PDRA became highly embedded in CEO's day-to-day routines. In particular, the CI became rather close to the management team, and was instrumental in helping them to collate staff feedback informing the commissioning of a new client management system. ${ }^{5}$ For her part, the PDRA forged a close relationship with the team of "floor" staff and, during the course of the research, fed back some junior staff members' concerns about the organizational restructuring underway. The PI 
played an active role in the conduct of fieldwork, but his interactions were more occasional, and mostly involved attending board meetings and managing the relationships with CEO's Director and the chair of the board.

These distinct roles meant that information was initially gathered in each context and then circulated in our team meetings. CEO staff knew that a "team" was conducting the research but much of what they imparted to us depended on the specific context and which research team member was in the field at that particular moment. While research team meetings were not hierarchical, unlike the "front stage" team performance, our growing awareness of the stratified nature of our ethnographic fieldwork also came to shape aspects of our "back stage" interactions. The CI and PDRA often found themselves "speaking for" specific cohorts of CEO staff within research meetings, voicing the concerns of those to whom they felt closest (Creese and Blackledge 2012) and which they knew could not be accessed or represented by any other team member. Similarly, the PI's contribution often included something akin to a "Director's" report, delivering information about and interpretations of emerging issues and policy directions drawn from attendance at board meetings and informal one-to-one chats with CEO's Director-sources to which no other team member had the same degree of access. Over the course of the research project, the team qua team-rather than as individuals-had to make collective judgments as to the sensitivity of what they had been told, and therefore what could freely circulate in each of our continuing personal interactions with CEO staff-and what could not. In short, we were very careful not to feed information learned at one "layer" of the organization into another if we judged it to be too sensitive.

In the course of the research we also became aware of the extent to which gender (coupled with career seniority) was affecting the research. CEO is a predominantly female work context. At the time of writing, of the core workforce of 20 staff, only four were male. We found that the CI and PDRA "fitted in" to CEO not only in terms of gender and age but also in the way they comported themselves in the field: we often noted the friendly and supportive atmosphere that characterized the working environment, and contributing to this was key. As a result, the CI and PDRA were able to move around CEO freely and unobtrusively, accessing spaces that the partner organization would have been entitled to keep private. Crucial accounts and nuances were often imparted informally, in brief conversations, over cups of coffee and occasionally outside of the workspace. The PI's relationship to CEO's staff was qualitatively different from that of the CI or PDRA. Known for his various roles in the policy field and as a senior academic figure, his occasional visits to the office for meetings were appreciated, and cordially received, but they were not routine. It was recognized that his principal points of liaison were with the Director and the board and, as such, he was not able to move around the organization as freely as the CI or the PDRA.

Recognition and management of these issues, of course, involved a degree of reflexivity. Whilst reflexivity is often understood as an individual pursuit, Barry et al. $(1999,31)$ state that it can and should be a part of team working, noting that "a team approach [to reflexivity] requires both individual and group reflexivity, with a dialogue between the two." As experienced ethnographers, committed to "good" research practice, this meant paying close attention to the roles played by each individual, as well as to the shifting place of the team in the field. Consequently, in order to mitigate potential problems regarding the division of labor within the team, we met frequently, particularly during the data-collection stage of the research. However, while initially driven by purely practical demands, our regular meetings became increasingly important as the project 
progressed, in that they became as much about developing an interpretation of our findings as about reporting back and planning future strategy.

\section{PIVOTAL MOMENTS}

In this section, we describe and analyze four key events that constituted pivotal moments in the Supporting Creative Business project. These were, first, an organization-wide staff meeting on June 4, 2013, held at CEO; second, a knowledge exchange event held at the University of Glasgow on November 11, 2013; third, a board meeting on September 25, 2013, held at CEO, and fourth, the research team's presentation at the AHRC's Creative Economy Showcase in London on March 12, 2014, at which CEO's Director appeared alongside the research team to discuss the experience of knowledge exchange from the point of view of the "partner" organization. ${ }^{6}$ Events such as these should not be understood simply as "mirrors," or key scenes in an organization's life that merely reflect what was going on within - and without - the organization at that particular moment in time. Rather, we propose that these moments be understood as performative: they are productive spaces in which the organization is brought into being (Cranston 2014; McCann 2011). This understanding of key events represents the team's approach more generally, where "the organization" is understood as a set of spatially and temporally located practices, rather than as a discrete, bounded "object" of study (Del Casino et al. 2000).

\section{Researchers' Presence and Non-Presence at a Key Staff Meeting}

Much in line with Schwartzman's $(1986 ; 1993)$ analysis, which argues that meetings are vitally important spaces where organizations seek to align intention with action, we found that the CEO staff meeting of June 4, 2013, was an early, pivotal moment for our project. It was important in two ways. First, it constituted a space in which our ethnographic team came into its own by demonstrating the way that we collected data and, furthermore, we also performed our role hierarchically to match the hierarchy of our partner organization. Second, it was an occasion when managerial strategy - driven by changes in the Scottish cultural policy field, cultural support milieu, and funding landscape-was disclosed to core CEO staff. The meeting therefore acted as what McCann $(2011,117)$ calls a "site of persuasion" within which abstract policy drivers, and the managerial understanding and translation of policy into discourse, become a basis for future organizational action.

The staff meeting was a day-long event, and split into three sections: in the first, CEO's advisers met, and reported back on trends witnessed in advice sessions over the past quarter. The second part of the day involved all CEO staff, who were present as the Director unveiled a new organizational structure, ${ }^{7}$ designed to "future-proof" the agency in light of significant changes in the creative sector. In the third part of the day, members of CEO's extended network of non-core staff met and reported back on trends that they had witnessed in recent months.

The CI and PDRA attended all three parts of the day. In the first session, the atmosphere was open, honest and - at times - celebratory, because adviser meetings were relatively rare and represented a valued opportunity for both personal and professional dialogue. In this meeting, both the CI and PDRA were able to sit in and take notes unobtrusively, without individual 
staff members feeling unable to speak freely. In the second part of the day, the atmosphere was much more tense. CEO staff had, in recent years, lived and worked through a prolonged period of organizational upheaval, and while the Director worked hard to persuade them that a new structure was needed and that the transition need not be too difficult, it was apparent that the staff were fatigued by constant change. Furthermore, as there had been no consultation period, staff were surprised that the new structure was due to come into effect immediately.

The CI's and PDRA's immersion in the organization enabled them to sit in on this meeting without in any way affecting its tone or content, and to take extensive notes. Moreover, despite the highly charged nature of the discussion, the CI and PDRA were able to ask for clarification on certain points; crucially, each did this with one eye on the staff "cohort" with which she was most closely aligned, thereby reinforcing the perceived stratification of the research team. They also began to use their own positions in the research team by deploying their growing sense of how each of the other research team members had been positioned by CEO. Specifically, the PDRA was acutely aware of asking a question — regarding the extent of staff consultation prior to the restructure - that she felt might be perceived as slightly "cheeky," but chose to do so anyhow because she felt it led to an important clarification and thought it would constitute less of a challenge coming from her than if it came from the CI.

In a short, mutual debriefing conversation after the second session, the CI and PDRA agreed that the meeting would most likely have taken on a different complexion had the PI been present, in that CEO staff would have been less comfortable with a relatively unfamiliar figure sitting in.

\section{Managing Researcher Criticism at a Knowledge Exchange Workshop}

In line with our original research proposal, submitted to the AHRC in May 2012, the knowledge exchange component of our project required the research team to organize three knowledge exchange events. It is to the first of these-known within the team as "KE1" - that we now turn our attention. KE1, a plenary meeting with all the staff and the chair of the board, was held in November 2013, some five months after the staff meeting just described. In the interim, we had conducted interviews with core CEO staff as well as the extended network of non-core staff and clients. We had also continued with our participant and non-participant observation, and had witnessed first-hand the teething problems caused by the new organizational structure.

At KE1, we reported back on some of our early research findings, including an examination of CEO's history since its inception in 2002 and our initial thoughts about the organizational restructuring. All of CEO's staff, from the Director "downwards," attended the event. KE1 was held in the university's spacious Senate Room. The choice of location was important, because after several months of becoming embedded in CEO's office space and their day-to-day routines, we felt it necessary to show CEO our own working environment. KE1 was the first time that CEO staff had been exposed to the way that we functioned as a research team outside the field. If, during the fieldwork period, we often performed as three separate but clearly interlinked researchers, each with a position that mirrored the hierarchy within CEO, within our own space-the university-we appeared as a coherent unit. The potential confusion and disruption that could have been caused by this shift in performance cannot be underestimated; hence individual team members found it necessary to oscillate both between the roles that we had performed in the field and those that we performed outside the field. 
The importance of this oscillation is illustrated by the Director's reaction to some of the material contained in the presentations made on the day, and the subsequent Interim Report. The PDRA, in particular - who had spent a considerable amount of time embedded within CEO, and clearly had been the most "visible" researcher around the organization for some months-critiqued the new organizational structure, and the way that it had been communicated and implemented. Her presentation was based on staff and client interview material. As a team, evidently we felt our co-written—but individually presented-material was fair, and supported by empirical evidence. However, it later emerged that the Director was unhappy with what she saw as premature criticism. $^{8}$

The team discussed KE1 in a meeting shortly after the event and noted the important role that our perceived hierarchy had played in the exchange of information. We judged that, despite the sharp reaction by the Director to the PDRA's presentation, it was necessary for the PDRA to be the one to pass on this criticism, and that to have done otherwise would have run the risk of appearing misleading (at best) and conspiratorial (at worst).

There were three reasons for this. First, reporting back the junior staff's concerns was necessary because it was a material finding. A failure to air some of their concerns would have looked like indulging the Director. ${ }^{9}$ It was essential for the PDRA to ensure that her relationship with junior staff was undamaged. Second, this critique could have come only from the most immersed researcher, because it was precisely the extent of her immersion that provided credible access to the material presented. Third, we concluded that, had we taken an alternative tack and nominated the board-aligned PI or management-aligned CI to take on the role of critic in front of the assembled CEO staff, this would have caused the Director embarrassment because of the level at which the criticism might be seen to come.

While it was clear from what we collectively chose to present that we did talk amongst ourselves as a team, sharing the different layers of information we had gathered, to maintain a distinction between the roles played at the formal level of our presentation was very important. On subsequent reflection, by then we had already recognized that had the CI or PI passed on this critique, the collective interchanges and evaluations conducted by our team outside the field would have been thrown into sharp relief. Performatively, we would have highlighted the difference between our "front stage" team personas and our "back stage" team dynamic, potentially undermining the comfortable and effective roles which we had adopted for the fieldwork. Due to her more junior staff position and greater immersion in the field, the PDRA was also uniquely able to defuse the palpable tension by slipping convincingly and quite naturally from "you" to "we" as she discussed the staff experience of the restructure. This "slip" produced smiles and laughter all round, and a quip from the CI about her "going native" may have suggested that some distance existed between the PDRA and the two senior team members.

\section{Being Discreet about a Hyper-Sensitive Board Meeting}

The PI attended board meetings throughout the fieldwork. In the board's minutes, he was designated formally as an observer, but it quickly became apparent that he was expected to engage in discussion at various points as well as sometimes quite explicitly to be used as a source of advice. On September 30, 2013, about halfway through our fieldwork, a crucial board meeting took place. On that occasion, CEO's chair proposed to resign. ${ }^{10}$ The PI was privy to a very passionate 
and revealing meeting and, in the usual way, the team later discussed the issues raised. Clearly, the wider background factors that had led to this potential crisis of leadership were of major importance for CEO and the continuing fieldwork and interviews by all the team. While the PI could obviously discuss this moment of crisis at subsequent meetings with the Director and chair, the other team members did not feel they could do so, nor even indicate that they were aware of it. Nor could they even hint at their knowledge of a crisis in the board to CEO's staff when going about their observations and interviews. So far as this matter was concerned, we explicitly made use of a selective firewall and were successful in maintaining discretion.

The crisis arose because the chair had concluded that CEO could not develop further without longer-term assured funding. It was revealed that, at a crucial meeting with CEO, the Scottish Government and Creative Scotland had attempted (in the phrase used) to "give comfort" that core funding would be available for the following year. The chair thought this assurance was insufficient and did not meet CEO's ambitions. His angst about the future was also tied to his wish to establish a new, influential place for CEO in the Scottish agency landscape.

The precise details of the policy background need not detain us further, other than to note that they underlined the research team's sense of CEO's precarious status as an organization that was not especially loved by the powers that be. The chair's dramatic reaction at the board meeting to CEO's key funders' refusal to recognize the agency's broader case for change in the agency landscape revealed how it stood in the power brokers' estimation. The chair, who was particularly invested in bringing about institutional change and a policy rethink for the creative economy, was reluctant to step back from the brink. After lengthy exchanges, however, he was persuaded by the other board members to withdraw his resignation, for the moment at least. It was clear at that meeting — as subsequently transpired - that he had already determined on stepping down soon.

This incident revealed two asymmetries. First, between the confidential discussions inside the board and the knowledge of CEO's staff; second, the knowledge circulating inside the research team and its own differentiated relationship to CEO's staff, on the one hand, and CEO's leadership, on the other. Once again, Goffman's (1959) distinction between actions performed "front" and "back" stage for the presentation of self is pertinent. The board's deliberations were kept back stage from the rest of CEO but witnessed front stage by the PI. The research team as a whole was privy to this sensitive back-stage information, but its own front-stage performance in conducting fieldwork inside CEO ensured that what might prove to be damaging if leaked was kept quietly back stage, staying firmly in the shadows.

\section{A Collusive Performance of Daytime KE}

On March 12, 2014, the project team attended a major promotional event organized by the AHRC. Held at the new and gleaming King's Place Conference Centre, in the burgeoning creative quarter springing up near King's Cross Station in London, the main point of the Showcase was to demonstrate to government ministers and creative industry figures the value of investing in research in what was lauded at the meeting as the UK's fastest-growing business and industrial sector-the creative economy. ${ }^{11}$ Of course, the Showcase was also a space for researchers to find out what their academic peers had been doing, but we consider this aspect to have been secondary in importance to the PR exercise. 
The key point for present purposes is that we had to perform our ethnographic teamwork in a corporate setting at an event "produced" by a specialist team, on which much money had been lavished to impress the powerful and influential. As it was a show, appropriately enough, we were offered a stage from which to present our findings, for which we chose the mildly intriguing title "Inside the Agency: Ethnography and Knowledge Exchange." We had decided that the best way to demonstrate that something akin to knowledge exchange had indeed occurred in our project would be to complete the session with an interview with CEO's Director, bringing out her perspective on what had been achieved alongside our own. Both we, and she, were well aware that this was a joint performance needing special preparation and, moreover, that it had been selected for streaming on the day and eventual posting on YouTube.

This high-profile public setting was in stark contrast to the previous week when, on March 3, 2014, we had held our end-of-project seminar-more matter-of-factly titled "Researching Cultural Enterprise Office" —in the stolid wood-panelled Melville Room at the University of Glasgow, surrounded by serious-faced portraits of Principals past rather than video cameras. That event had been conceived as a roundtable. With two dozen specially invited participants from government, cultural agencies, think tanks, academia, and comparable bodies to CEO from Denmark, Norway, and the US, it was intended as a private, systematic sounding board for our findings. We had constructed the sequence of presentations to give CEO's Director and chair the last word and to air their views on the value — or otherwise — of the research we had conducted.

For the Showcase, our preparation was quite different. We had to envision an audience of all-comers, about whose knowledge or interest we could assume nothing. We therefore had to present the rationale for our work with great explicitness as well as decide just how much detail would illuminate — and not bore-those present. We were also acutely aware of being a Scottish team in London. That meant treading a tightrope of necessarily talking about the Scottish context of our research while, at the same time, demonstrating its general relevance to debates about public intervention in the creative economy.

Seated on deep sofas, we presented our work from a podium with a large screen behind us onto which our slides were projected. It was more like being on a daytime TV studio set than inside a seminar room. The audience, seated at round tables well suited to diners viewing a cabaret or taking in a jazz set, was barely visible due to the powerful studio lighting trained on the presenters.

We conformed to our setting and fell into what had become our standard way of presenting our findings, once again enacting our hierarchy in public. First, the PI gave a brief introduction to the project, underlining its Scottish context and how this fitted into the UK's policy debates, also noting that we would conclude the event with an interview. Then, the CI presented a short account of CEO's history, organization, and geographical range. This was followed by the PDRA's account of how CEO dealt with its clients and its own precariousness. Finally, the PI addressed the question of knowledge exchange and what the team had learned from its research. After a brief pause, he turned to CEO's Director and conducted an interview with her.

On this occasion, both researchers and researched had a common interest in enacting a jointly agreed process of knowledge exchange for an invited but unknown public. Above all, both parties wanted to demonstrate the value of knowledge exchange, but from different perspectives. Although the interview itself was not rehearsed, the PI had sent CEO's Director a list of the questions he intended to raise. She had been invited-in effect - to collaborate in a performance of knowledge exchange, and knew beforehand that she would be there to offer her own views about the value of academic research. 
The interview illuminated very clearly what the Director had wanted from the research and how she saw knowledge exchange. She told the audience that she had been inspired by the experience of another agency in the US, which had commissioned an anthropologist to undertake its evaluation. She hoped that a new narrative might emerge from the present study that would be of help with CEO's funders and convey the value of her agency's activity to the "stakeholders" in a novel way. She was also very clear about the difference between a consultancy and a piece of academic research, and why the latter mattered just now:

[W]e were ten years in and it was really a point to... consolidate and develop or consider doing the opposite of that. So it was definitely time for a real change and I'd been kind of toying with the usual economic development consultation evaluations... and though they kind of found some good things, they always felt like a bit of a drive-by shooting. And, you know, they'd leave and we'd get a report and yet actually the real value of the work... and why it's important for the sector was never really caught and... it never gave us a really useful argument to really start to inspire the policymakers that we're working quite closely with.

The Director was also well aware that she had taken a calculated risk by opening the doors and that the research had taken place just as the organization was facing the challenge of changing its structure:

[T]here was a sense of change fatigue, you know, that had definitely started to creep in. And in many ways I think it was this project that really helped everybody make meaning again out of, you know, what we're doing and why we're doing it.

Without having seen the final analysis of CEO's work, she had already found that the work to date had forced her to reappraise some past decisions "and really start a kind of process of reframing our delivery model and thinking about certain things that you just become attached to and maybe it's time to let those go." The very fact of the research, she thought, had added to CEO's credibility for "our key funders, the government, the stakeholders and the kind of conversation that we're having now which has come out of this research."

The Director's eloquent performance was one in which she expressed a very positive view of what this kind of research could bring, while realistically recognizing that while it could not solve CEO's problems, it could stimulate questions that were productive for future strategy.

\section{CONCLUSION}

Writing an article on team ethnography such as this is likely to be provoked by one of two sets of circumstances: working out what went wrong or working out what went right. For us it has been the latter, and specifically our desire to analyze and convey an account of the positive team dynamic that emerged during the fieldwork, rather than being designed in advance of it. In our back-stage interactions we have sought to be as democratic as possible. Consequently, we have consequently chosen to work in ways that, so far as practical, resist the prevalent norms of academic practice in funded research projects. But there are, of course, limits to the degree to which this is possible. In addition to inequalities of experience, ultimately, the PDRA had a fixed contract and the PI was responsible for delivering on the grant. 
We have drawn on Goffman (1959) to characterize the distinction between our frontand back-stage team performances but, in line with that thinking, it is crucial to stress that our front-stage work should not be understood as calculated to mislead. Rather, evolving a more overt performance of our team hierarchy in situ was both a necessary and legitimate response to what the field threw up; it was built up by a series of incremental and intuitive decisions, taken severally in order to connect with our research subjects in meaningful ways.

This occurred because the intersection of careers within research teams observed by Platt $(1976,12)$ is only one of the dynamics in play in this kind of project. From the moment that it moves into an organization, the team-both collectively and as individuals-also intersects with people occupying a variety of career stages and professional perspectives in the researched organization. In our case-where there was continuing fieldwork within a single organization and a need for all to make this comprehensible and legible-all parties (both ourselves and CEO personnel) slipped into an analogous mapping of one structure onto the other. This was central to building trust and creating shorthand for day-to-day communication. Given the oneyear timescale, we have concluded that it was the only practical option. For a longer-term project, however, it might have been possible and productive to deliberately disrupt at least some elements of this structure, switching roles and increasing the range of research perspectives on each aspect of CEO's work. However, it seems unlikely that anyone but the PI would have been able to operate as effectively at boardroom level, and it is equally hard to imagine either of the more senior team members being able to access the kinds of frank confidence at junior level that the PDRA did.

In addition to meeting the demands of the project's short duration, its shape and nature determined other ways in which we worked. In particular, having to track rapid developments within CEO, and managing the front-stage/back-stage flow of information about these, created the need for unusually frequent team meetings during the data-gathering stage. These quickly became really important sites of interpretative work, feeding back into each subsequent phase of the fieldwork we conducted, as well as reinforcing our sense of team identity. Another factor determining the frequency of team meetings was the schedule of KE events, which required us to assemble our thoughts early and articulate them clearly to different internal and external audiences.

In this article, we have chosen to narrate our account of the teamwork by recounting some pivotal moments, both front and back stage. Such events occurring in the field may be understood as more than simply snapshots of an organization, being not merely illustrations of actual teamwork but productive spaces in which the team was made. To write this is to offer a retrospective take. The encounters in question were either witnessed in fieldwork or devised to achieve KE, rather than to build the team. But, as we take our distance at this project's conclusion, we can see clearly how such pivotal moments have been the means by which the research team's working practices and its growing sense of itself as a team were, in fact, produced over the course of the project. Inevitably, so far as possible, the collaborative work of writing reflexively about our ethnographic teamwork has endeavored to transform the implicit into the explicit. Formalizing our collective reflections, and in this way settling on a means of telling, has permitted us to articulate the constitutive practices of ethnographic teamwork. 


\section{ACKNOWLEDGMENTS}

We are indebted for the indispensable and generous help given by the staff and board of Cultural Enterprise Office; in particular, Deborah Keogh, Bob Last, and Fiona Pilgrim. Thanks are also due to Dr. David Lee, Prof. Angela McRobbie, and Dr. Shani Orgad for their useful comments on an earlier draft of this article.

\section{FUNDING}

"Supporting Creative Business: Cultural Enterprise Office and its Clients" was supported by the UK Arts and Humanities Research Council, grant reference: AH/K002570/1. The authors gratefully acknowledge the AHRC's support for this research.

\section{NOTES}

1. As space does not permit us to take the matter further here, we note this point and will address it in a companion article. We also note that, increasingly, the social sciences are attracted to the concept of co-production, an idea that has some lines of congruence with KE, and the closely related concept of "impact." However, Pain et al. $(2011,184)$ contrast formal, measurable, Research Councils UKformulated requirements such as $\mathrm{KE}$ and impact with co-production, emphasizing the grassroots focus of the latter: "[w]here knowledge is co-produced, impact is two-way: research may inform society, but its own agendas, design, conduct and outcomes are also profoundly informed and shaped by various users, publics and participants." Whilst we are sympathetic to Pain et al.'s (2010) attempt to emphasize the radical, epistemological potential of co-production, not all approaches fit this model.

2. There is a risk of being recursive here. "Creative" has become a widespread and ill-defined term, in line with the increased attention paid to those who work in the "creative economy."

3. Including a competitive scheme for start-ups, Starter for 6; an incubator called Fashion Foundry; and, for more established businesses, the Flourish mentoring program.

4. While CEO's key relationships are with the Scottish Government and Creative Scotland, it also has to manage its connections with other players on a rather cluttered stage: Scottish Enterprise, Highlands and Islands Enterprise, Business Gateway, and Skills Development Scotland. Together, these bodies constitute the Scottish Cultural Industries Partnership (SCIP), which is meant to ensure a coherent and consistent approach to the creative economy. At this time of writing, SCIP's functioning is under review.

5. The client management system is an online repository that stores information about CEO clients and drives the content of their website.

6. This presentation is available to view on YouTube: https://www.youtube.com/watch?v= $8 \mathrm{JdxCe} 0$ atqg \& feature=youtu.be

7. In some respects, the unveiling of the structure was intended as performative, signalling a break; however, the old structure, routines, and practices were so embedded that the new structure could not cleanly supersede the old one.

8. On subsequent reflection, the Director accepted much of this critique, which was concerned primarily with the lack of staff consultation prior to the restructure, and the confusion that resulted as staff attempted to adjust to the new organizational structure.

9. Although it must be noted that the junior staff felt we did not go far enough in critiquing the new structure, and how its launch had been communicated.

10. Lest it be thought that we have thrown discretion to the winds, permission to reveal this incident was requested from the former Chair of CEO and readily granted.

11. The Centre for Economics and Business Research $(2013,17)$ has claimed that the creative industries make a $£ 5.8$ bn per annum contribution to the UK economy. 


\section{REFERENCES}

Barry, C., N. Britten, N. Barber, C. Bradley, and F. Stevenson. 1999. "Using Reflexivity to Optimize Teamwork in Qualitative Research." Qualitative Health Research 9 (1): 26-44.

Centre for Economics and Business Research. 2013. The Contribution of the Arts and Culture to the National Economy. London: CEBR.

Clerke, T., and N. Hopwood. 2014. Doing Ethnography in Teams: A Case Study of Asymmetries in Collaborative Research. London: Springer.

Cranston, S. 2014. "Reflections on the Doing the Expat Show: Performing the Global Mobility Industry." Environment and Planning A46 (5): 1124-1138.

Creese, A., A. Bhatt, N. Bhojani, and P. Martin. 2008. "Fieldnotes in Team Ethnography: Researching Complementary Schools." Qualitative Research 8 (2): 197-215.

Creese, A., and A. Blackledge. 2012. "Voice and Meaning-Making in Team Ethnography." Anthropology and Education Quarterly 43 (3): 306-324.

Del Casino, V. J., A. J. Grimes, S. P. Hanna, and J. P. Jones. 2000. "Methodological Frameworks for the Geography of Organizations." Geoforum 31 (4): 523-538.

Döös, M., and L. Wilhelmson. 2014. "Proximity and Distance: Phases of Intersubjective Qualitative Data Analysis in a Research Team." Quality \& Quantity 48 (2): 1089-1106.

Economic and Social Research Council (ESRC). 2014. "ESRC Impact Toolkit 2013." Available at: http://www.esrc.ac. uk/funding-and-guidance/impact-toolkit/. Accessed May 5, 2014.

Erickson, K. C., and D. Stull. 1998. Doing Team Ethnography: Warnings and Advice. Thousand Oaks, CA: Sage

Gerstl-Pepin, C. I., and M. G. Gunzenhauser. 2002. "Collaborative Team Ethnography and the Paradoxes of Interpretation." International Journal of Qualitative Studies in Education 15 (2): 137-154.

Goffman, E. 1959. The Presentation of Self in Everyday Life. London: Penguin.

Gupta, A. 2014. “Authorship, Research Assistants and the Ethnographic Field.” Ethnography 15 (3): 394-400.

Kitagawa, F., and C. Lightowler. 2013. "Knowledge Exchange: A Comparison of Policies, Strategies, and Funding Incentives in English and Scottish Higher Education.” Research Evaluation 22 (1): 1-14.

Mauthner, N. S., and A. Doucet. 2008. "Knowledge Once Divided Can Be Hard to Put Together Again: An Epistemological Critique of Collaborative and Team-Based Research Practices." Sociology 42 (5): 971-985.

McCann, E. 2011. "Urban Policy Mobilities and Global Circuits of Knowledge: Toward a Research Agenda." Annals of the Association of American Geographers 101 (1): 107-130.

Middleton, T., and J. Cons. 2014. "Coming to Terms: Reinserting Research Assistants into Ethnography's Past and Present." Ethnography 15 (3): 279-290.

O'Connor, J., and X. Gu. 2010. "Developing a Creative Cluster in a Postindustrial City: CIDS and Manchester." The Information Society 26 (2): 124-136.

Pain, R., M. Kesby, and K. Askins. 2011. “Geographies of Impact: Power, Participation and Potential.” Area 43 (2): $183-188$.

Platt, J. 1976. Realities of Social Research: An Empirical Study of British Sociologists. Londong: Sussex University Press.

Prince, R. 2014. "Consultants and the Global Assemblage of Culture and Creativity." Transactions of the Institute of British Geographers 39: 90-101.

Schlesinger, P. 2009a. "Creativity and the Experts: New Labour, Think Tanks, and the Policy Process." International Journal of Press/Politics 14 (1): 3-20.

Schlesinger, P. 2009b. "The SNP, Cultural Policy and the Idea of the "Creative economy." In The Modern SNP: From Protest to Power, edited by G. Hassan, 135-146. Edinburgh: Edinburgh University Press.

Schlesinger, P. 2013. "Expertise, the Academy and the Governance of Cultural Policy." Media, Culture \& Society 35 (1): 27-35.

Schwartzman, H. B. 1986. "The Meeting as a Neglected Social Form in Organizational Studies.” In Research in Organizational Behaviour, edited by B. L. Staw and L. L. Cummings, 233-258. Greenwich, CT: JAI Press.

Schwartzman, H. B. 1993. Ethnography in Organizations. London: Sage.

Scottish Government. 2013. Scotland's Future. Edinburgh: Scottish Government.

Woods, P., M. Boyle, B. Jeffrey, and G. Troman. 2000. “A Research Team in Ethnography.” International Journal of Qualitative Studies in Education 13 (1): 85-98. 